\title{
The unusual presentation of a vascular injury after lumbar microdiscectomy: case report
}

\author{
Daniel Huttman, MD, Mathew Cyriac, MD, MBA, Warren Yu, MD, and Joseph R. O’Brien, MD, MPH \\ Department of Orthopaedic Surgery, George Washington University, Washington, DC
}

\begin{abstract}
Vascular injury during lumbar spine surgery is a relatively rare complication but can have devastating outcomes. The injury may not be apparent during surgery and can present acutely or late in various manners, and some injuries can be asymptomatic. This report discusses the unusual case of a 35-year-old woman who underwent a right L4-5 microdiscectomy for disc herniation and 4 days postoperatively presented with a pulmonary embolus. A subsequent CT scan revealed a pseudoaneurysm and arteriovenous fistula of the right common iliac vein and artery, which gave rise to the embolus. The patient received a right iliac artery stent, and at 4 months after surgery she continues to be symptom free. This report describes the atypical presentation of vascular injury after lumbar microdiscectomy and stresses the importance of cautiously using the pituitary rongeur when removing deeper disc fragments.
\end{abstract}

http://thejns.org/doi/abs/10.3171/2015.7.SPINE14256

KEY WORDS lumbar microdiscectomy; arteriovenous fistula; vascular injury; lumbar disc herniation; pulmonary embolus; technique

$\mathrm{T}$ HE posterior approach to the lumbar spine is the most commonly used approach for treating lumbar spine pathology. Depending on the pathology, the incidence of complications following lumbar spine surgery is between $2 \%$ and $30 \%, 1,9,23$ and vascular injuries represent an infrequent number of complications. Although vascular injuries occur at a low frequency during lumbar spine surgery, they are among the most feared complications due to their potentially life-threatening consequences. . $^{4-8,10,13,14,19,21,24,27}$

Vascular injuries during lumbar spine surgery may involve injury to the arterial blood supply, venous blood supply, or both. Acute lacerations to the arterial blood supply can present in various ways, from massive hemorrhage to small changes in blood pressure, heart rate, and end-tidal $\mathrm{CO}_{2}$. Many arterial injuries are identified intraoperatively or shortly thereafter. $2,3,7,8,10-13,18,19,21,24,26,27,30,33$ Venous injuries do not always manifest as acutely and can be missed for years postoperatively. ${ }^{2,4,5,9,13,15,17,31}$ Late presentations range from asymptomatic to high-output cardiac failure that causes death from an undiagnosed arteriovenous fistula (AVF). In this report, we present the case of a patient with AVF and pseudoaneurysm formation after lumbar micro- discectomy. Although these are usually diagnosed late, our patient presented acutely with a pulmonary embolism due to a thrombus that formed at the vascular injury site.

\section{Case Report}

This 35-year-old woman had a body mass index of 28.3 $\mathrm{kg} / \mathrm{m}^{2}$ and no medical history. She experienced intractable right leg pain and weakness that lasted for several months. MRI revealed a right-sided L4-5 disc herniation with nerve root compression (Fig. 1). The anterior longitudinal ligament was noted to be intact on the MR image (Fig. 1), and she did not have any evidence of instability at L4-5. After nonsurgical treatment failed, the patient elected to undergo right L4-5 microdiscectomy in the prone position. During the procedure, hemilaminotomy with removal of the medial portion of the facet was performed to visualize the intervertebral disc. The epidural veins were coagulated with bipolar cautery. The L-5 nerve root was exposed and retracted medially, and a $1 \times 3.5-\mathrm{cm}$ annular fragment was removed using a pituitary rongeur. The pituitary rongeur was again inserted deeper to grab any loose intradiscal fragments. The disc was irrigated with

ABBREVIATIONS AVF = arteriovenous fistula. 


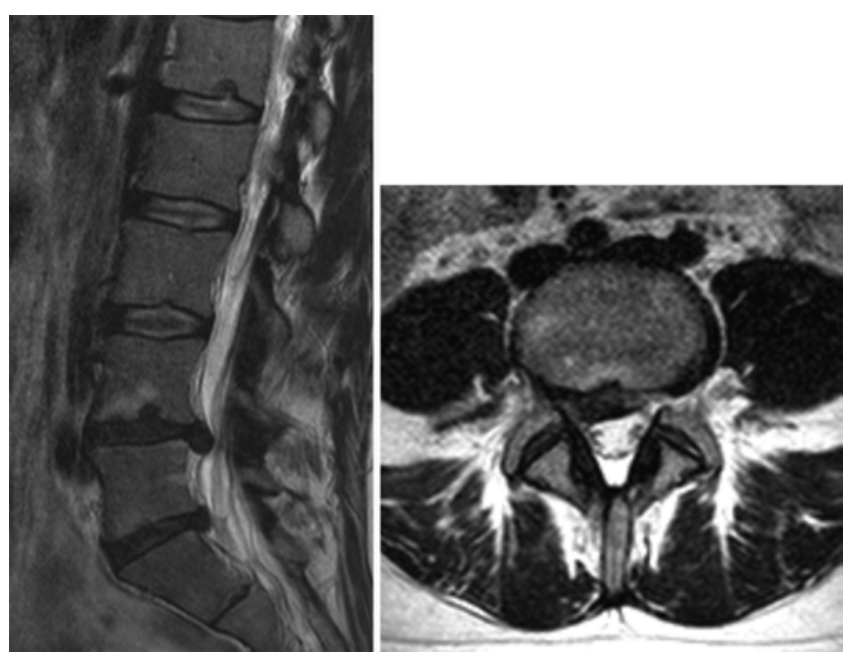

FIG. 1. Preoperative sagittal (left) and axial (right) T2-weighted MR images showing a right-sided $L 4-5$ disc herniation.

an angiocatheter to remove any loose leftover fragments. Adequate hemostasis was noted after Gelfoam sponges (Pfizer) were applied. During the entire procedure, no excess bleeding was noted. The wound was closed in a standard fashion. The estimated blood loss was less than $30 \mathrm{ml}$, and the operative time was 51 minutes. The patient was admitted overnight. On postoperative Day 1, her preoperative right leg pain had significantly improved and she was discharged home.

The patient returned to the emergency department on postoperative Day 4 and complained of shortness of breath. The patient's preoperative right leg pain had nearly resolved, and her right ankle dorsiflexion strength was improving. On presentation, she was tachycardic at $130 \mathrm{bpm}$ with normal oxygen saturation. She underwent CT angiography, which revealed a pulmonary embolism in the left lower lobe, pulmonary edema, and pleural effusion. The bilateral lower-extremity Doppler ultrasound examination was negative for deep venous thrombosis. She was admitted to the hospital and was placed on therapeutic enoxaparin with a bridge to warfarin to treat the pulmonary embolism.

During admission, she complained of worsening abdominal pain and increasing lower-extremity swelling. An abdominopelvic CT scan was obtained, which revealed a right common iliac artery and vein AVF with pseudoaneurysm and thrombus formation (Fig. 2). After consulting with the vascular surgery service, she underwent placement of a right common iliac artery stent on hospital Day 3 by interventional radiology. Following stent placement, she was monitored in the intensive care unit and received a heparin drip for 24 hours. After transfer from the intensive care unit, she was restarted on a regimen of enoxaparin and warfarin therapy. Repeat CT angiography showed appropriate stent placement with resolution of the AVF and pseudoaneurysm (Fig. 3). The patient was discharged home on enoxaparin while transitioning to warfarin for pulmonary embolism treatment. At her last follow-up at 4 months after surgery, she was symptom free without any lumbar reherniation or stent graft occlusion.
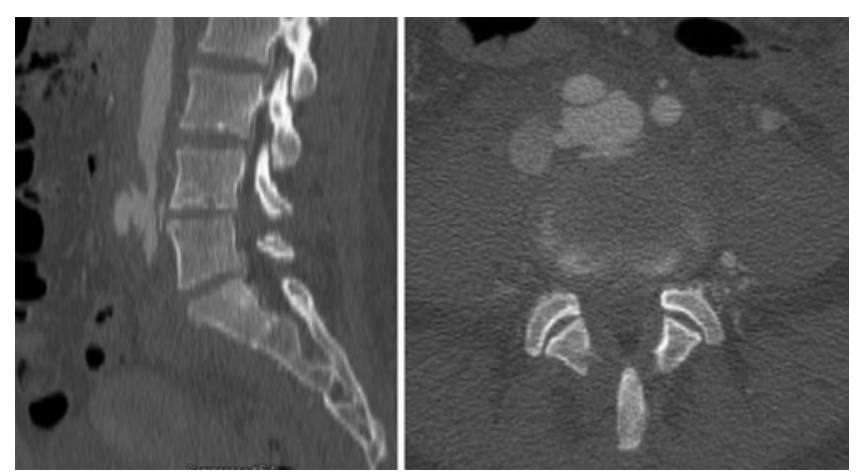

FIG. 2. Sagittal (left) and axial (localized to the L5-S1 disc) (right) postcontrast abdominopelvic CT showing the AVF and pseudoaneurysm of the right common iliac artery and vein, just inferior to the aortic bifurcation.

\section{Discussion}

The posterior approach is commonly used for lumbar spinal surgery and demonstrates a low complication rate between $2 \%$ and $20 \% .^{1,9,23}$ Although vascular injuries account for less than $1 \%$ of complications during these surgeries, ${ }^{4,5,15,16,29}$ they are one of the most feared complications and can have devastating consequences, including mortality. $6-8,10,13,19$

In 1945, Linton and White reported the first case of a vascular injury after lumbar discectomy resulting in AVF formation. ${ }^{22}$ Since then, many more cases of vascular injury during lumbar spinal surgery have been documented. The most common injury is a vascular tear, ${ }^{3}$ and its presentation varies from heavy bleeding to signs of shock including tachycardia and hypotension in the early postoperative period. ${ }^{4-7,9-13,15,18,19,28}$ Other vascular injuries, such as AVFs and pseudoaneurysms, are commonly diagnosed
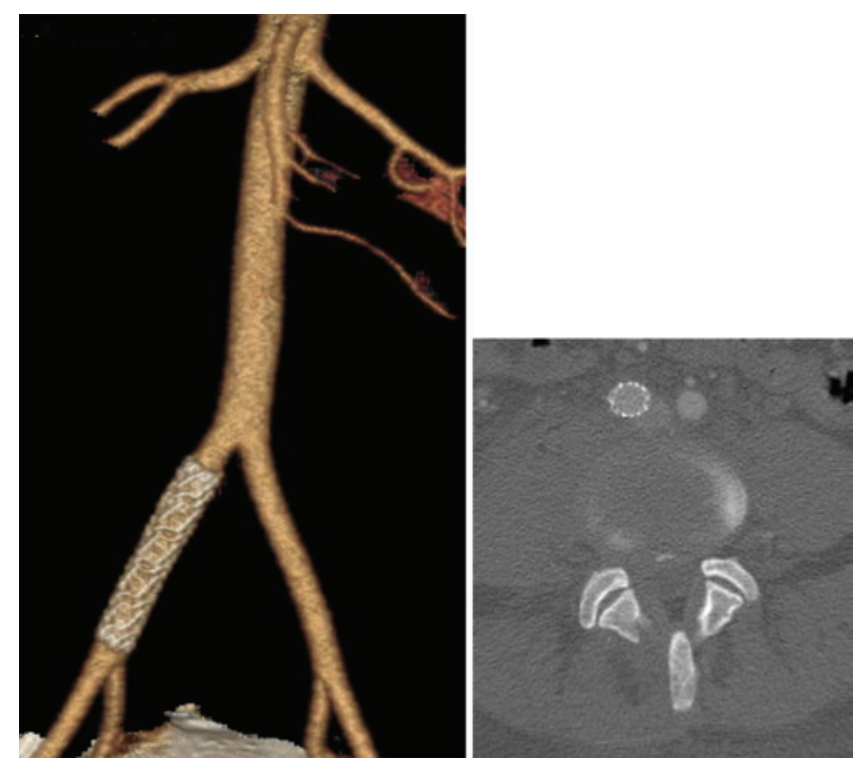

FIG. 3. Axial CT angiogram with reconstruction (left) and 3D reconstruction of the CT angiogram (right) after right common iliac artery stent placement, showing resolution of the AVF and pseudoaneurysm. Figure is available in color online only. 
in the late postoperative period. ${ }^{2} \mathrm{AVF}$ is the second most common type of vascular injury after lumbar spine surgery $^{3}$ and can have various presentations. While an AVF may be diagnosed in the early postoperative period, many are diagnosed late, sometimes up to a decade after surgery, ${ }^{3}$ with many different signs and symptoms leading to the diagnosis. The early diagnosis of an AVF is often due to high-output cardiac failure. ${ }^{11,18,26}$ Late diagnoses vary in presentation from leg edema, back pain, abdominal bruits, and pulsating masses to high-output cardiac failure. , $5,9,10,13-17,25,26$ While these symptoms may help lead to a diagnosis, up to $50 \%$ of patients with an AVF may be completely asymptomatic. ${ }^{19}$ A vascular injury presenting as a pulmonary embolism is also an infrequently reported complication after lumbar surgery $y^{4,13}$ and may manifest up to a year after surgery. ${ }^{4}$

While there are reports of massive hemorrhage into the operative field during surgery, vascular injuries are not always apparent during surgery. $5,6,9,10,13$ Vascular injuries to most of the blood vessels in the abdomen and pelvis have been documented ${ }^{32}$ and linked to aggressive use of the pituitary rongeur. ${ }^{12,20}$ As the rongeur tip passes the anterior longitudinal ligament and enters the abdominal space, it has the potential to injure the vessels within its vicinity. In our patient, the perforation of the anterior annulus was not felt during surgery. On further reflection, the performing surgeon thought that the pituitary rongeur was inserted deeper than usual. In the future, anterior annulus violation can be prevented by carefully noting any change in resistance when using the pituitary rongeur and how deep it is inserted. During this case, we were meticulous in maintaining hemostasis, but it is still possible that we may have missed light bleeding from the disc space. This case report stresses the importance of checking for any excess bleeding at the end of a microdiscectomy.

\section{Conclusions}

In this case report, we present the diagnosis and management of acute pulmonary embolism due to an undocumented vascular injury during lumbar microdiscectomy. Vascular injury during lumbar spine surgery is a relatively rare complication, but one that can have devastating outcomes. Although a vascular injury during lumbar spine surgery can present acutely as hemorrhage and shock, this case describes AVF and pseudoaneurysm formationwhich is commonly diagnosed years after the injury - that acutely presented as a pulmonary embolism. This case outlines the importance of a multidisciplinary approach when dealing with an uncommon presentation and cautiously using the pituitary rongeur when removing deeper disc fragments.

\section{References}

1. Baker JK, Reardon PR, Reardon MJ, Heggeness MH: Vascular injury in anterior lumbar surgery. Spine (Phila Pa 1976) 18:2227-2230, 1993

2. Bingol H, Cingoz F, Yilmaz AT, Yasar M, Tatar H: Vascular complications related to lumbar disc surgery. J Neurosurg 100 (3 Suppl Spine):249-253, 2004

3. Birkeland IW, Taylor TK: Major vascular injuries in lumbar disc surgery. J Bone Joint Surg Br 51:4-19, 1969

4. Brewster DC, May AR, Darling RC, Abbott WM, Moncure
AC: Variable manifestations of vascular injury during lumbar disk surgery. Arch Surg 114:1026-1030, 1979

5. Davis RA: A long-term outcome analysis of 984 surgically treated herniated lumbar discs. J Neurosurg 80:415-421, 1994

6. Desaussure RL: Vascular injury coincident to disc surgery. J Neurosurg 16:222-228, 1959

7. Ewah B, Calder I: Intraoperative death during lumbar discectomy. Br J Anaesth 66:721-723, 1991

8. Franzini M, Altana P, Annessi V, Lodini V: Iatrogenic vascular injuries following lumbar disc surgery. Case report and review of the literature. J Cardiovasc Surg (Torino) 28:727-730, 1987

9. Fritzell P, Hägg O, Nordwall A: Complications in lumbar fusion surgery for chronic low back pain: comparison of three surgical techniques used in a prospective randomized study. A report from the Swedish Lumbar Spine Study Group. Eur Spine J 12:178-189, 2003

10. Fruhwirth J, Koch G, Amann W, Hauser H, Flaschka G: Vascular complications of lumbar disc surgery. Acta Neurochir (Wien) 138:912-916, 1996

11. Gallerani M, Maida G, Boari B, Galeotti R, Rocca T, Gasbarro V: High output heart failure due to an iatrogenic arterio-venous fistula after lumbar disc surgery. Acta Neurochir (Wien) 149:1243-1247, 2007

12. Goodkin R, Laska LL: Vascular and visceral injuries associated with lumbar disc surgery: medicolegal implications. Surg Neurol 49:358-372, 1998

13. Gurdjian ES, Webster JE, Ostrowski AZ, Hardy WG, Lindner DW, Thomas LM: Herniated lumbar intervertebral discs - an analysis of 1176 operated cases. J Trauma 1:158 176,1961

14. Hanouz JL, Bessodes A, Samba D, Gérard JL, Bricard H: Delayed diagnosis of vascular injuries during lumbar discectomy. J Clin Anesth 12:64-66, 2000

15. Harbison SP: Major vascular complications of intervertebral disc surgery. Ann Surg 140:342-348, 1954

16. Inamasu J, Guiot BH: Vascular injury and complication in neurosurgical spine surgery. Acta Neurochir (Wien) 148:375-387, 2006

17. Jarstfer BS, Rich NM: The challenge of arteriovenous fistula formation following disk surgery: a collective review. $\mathbf{J}$ Trauma 16:726-733, 1976

18. Kelly JJ, Reuter KL, Waite RJ: Vascular injury complicating lumbar diskectomy: CT diagnosis. AJR Am J Roentgenol 153:1233-1234, 1989

19. Kwon TW, Sung KB, Cho YP, Kim DK, Ko GY, Yoon HK, et al: Large vessel injury following operation for a herniated lumbar disc. Ann Vasc Surg 17:438-444, 2003

20. Leavens ME, Bradford FK: Ruptured intervertebral disc; report of a case with a defect in the anterior annulus fibrosus. J Neurosurg 10:544-546, 1953

21. Lesoin F, Warembourg H, Asseman P: Fatal congestive heart failure associated with an iatrogenic caval aortic fistula following surgical removal of a herniated intervertebral disk. Surg Neurol 22:532, 1984

22. Linton RR, White PD: Arteriovenous fistula between the right common iliac artery and the inferior vena cava. Arch Surg 50:6-13, 1945

23. Nasser R, Yadla S, Maltenfort MG, Harrop JS, Anderson DG, Vaccaro AR, et al: Complications in spine surgery. $\mathbf{J}$ Neurosurg Spine 13:144-157, 2010

24. Papadoulas S, Konstantinou D, Kourea HP, Kritikos N, Haftouras N, Tsolakis JA: Vascular injury complicating lumbar disc surgery. A systematic review. Eur J Vasc Endovasc Surg 24:189-195, 2002

25. Prabhakar H, Bithal PK, Dash M, Chaturvedi A: Rupture of aorta and inferior vena cava during lumbar disc surgery. Acta Neurochir (Wien) 147:327-329, 2005 
26. Sadhasivam S, Kaynar AM: Iatrogenic arteriovenous fistula during lumbar microdiscectomy. Anesth Analg 99:18151817,2004

27. Sağdiç K, Ozer ZG, Senkaya I, Türe M: Vascular injury during lumbar disc surgery. Report of two cases; a review of the literature. Vasa 25:378-381, 1996

28. Sande E, Myhre HO, Witsøe E, Lundbom J, Stolt-Nielsen A, Anda S: Vascular complications of lumbar disc surgery. Case report. Eur J Surg 157:141-143, 1991

29. Stolke D, Sollmann WP, Seifert V: Intra- and postoperative complications in lumbar disc surgery. Spine (Phila Pa 1976) 14:56-59, 1989

30. Szolar DH, Preidler KW, Steiner H, Riepl T, Flaschka G, Stiskal M, et al: Vascular complications in lumbar disk surgery: report of four cases. Neuroradiology 38:521-525, 1996

31. Taylor H, Williams E: Arteriovenous fistula following disk surgery. Br J Surg 50:47-50, 1962

32. Tsai YD, Yu PC, Lee TC, Chen HS, Wang SH, Kuo YL: Superior rectal artery injury following lumbar disc surgery. Case report. J Neurosurg 95 (1 Suppl):108-110, 2001

33. Wu CY, Hung YN, Liu YH, Ko PJ: Endovascular treatment of iatrogenic iliac artery disruption in lumbar disc surgery. Ann Vasc Surg 23:255.e7-255.e11, 2009

\section{Disclosures}

Dr. O'Brien owns stock in Spinicity; works as a consultant for Globus, Stryker, and Relivant; and received clinical or research support for this study from Globus.

\section{Author Contributions}

Conception and design: all authors. Acquisition of data: all authors. Analysis and interpretation of data: all authors. Drafting the article: all authors. Critically revising the article: all authors. Reviewed submitted version of manuscript: all authors. Approved the final version of the manuscript on behalf of all authors:

O'Brien. Administrative/technical/material support: all authors. Study supervision: O'Brien, Yu.

\section{Correspondence}

Joseph R. O'Brien, Department of Orthopaedic Surgery, George Washington University, 2150 Pennsylvania Ave. NW, Washington, DC 20037. email: jobrien@mfa.gwu.edu. 